\title{
Possible neurocognitive benefits of exercise in persons with heart failure
}

\author{
Rachel Galioto, Andrew F. Fedor and John Gunstad
}

\begin{abstract}
More than 6 million Americans have heart failure (HF) and more than 500,000 are diagnosed each year. In addition to its many adverse medical consequences, HF is also a significant risk factor for neurological disorders like Alzheimer's disease and associated with cognitive impairment long prior to the onset of these conditions. Converging bodies of literature suggest cognitive dysfunction in HF may be at least partially modifiable. One key mechanism for cognitive improvement is improved cerebral blood flow, which may be possible with exercise in patients with HF. This brief review provides a model for the likely neurocognitive benefits of exercise in HF and encourages further work in this area.
\end{abstract}

Keywords: Heart failure, Exercise, Memory

\section{Introduction}

Heart failure (HF) has become an epidemic and nearly 6 million Americans have been diagnosed with this high risk condition [79]. Despite improved survival rates, the 5 -year mortality rate remains at 50-60\% [61, 82]. HF also represents a significant individual and financial burden from high rates of rehospitalization and medications costs. HF is the most common reason for recurrent hospitalization and costs approximately $\$ 30$ billion annually in the United States alone [35]. HF also produces significant psychosocial problems, including decreased functional independence and quality of life $[1,16]$.

\section{$\mathrm{HF}$ and neurocognitive function}

In addition to medical and psychosocial consequences, HF is a significant risk factor for neurological disorders including Alzheimer's disease, vascular dementia [75], and stroke $[103,104]$, and high rates of cognitive impairment even the absence of these conditions [97]. Recent studies show that the majority of individuals with HF evidence at least some cognitive impairment, while up to $25 \%$ demonstrate moderate to severe cognitive impairment on testing [17]. Deficits have been observed in many different domains including attention, executive function, learning and memory, language, visuospatial functioning and psychomotor speed $[6,14,17,32,74,97,98]$. Interestingly, a recent study in HF patients found that nearly

\footnotetext{
* Correspondence: jgunstad@kent.edu

Department of Psychology Sciences, Kent State University, Kent, OH 44242, USA
}

one quarter of the patients exhibited deficits in three or more domains of cognitive function [74]. The risk for cognitive dysfunction appears to increase with increasing HF severity [74, 97].

Cognitive dysfunction in HF is likely explained by a number of adverse brain changes that are also frequently observed in HF. Most commonly, patients demonstrate increased cortical atrophy [106], cerebral infarcts [4, 84], white matter changes [14] and metabolic alterations [60]. Specifically, patients with HF have been shown to have significantly less gray matter volume, especially in the insular cortex, frontal cortex, parrahippocampal gyrus, cingulate, cerebellar cortex and deep cerebellar nuclei [106] compared to controls. Additionally, HF patients exhibit increased amounts of periventricular white matter hyperintensities (WMH) and WMH in the basal ganglia [84, 99]. Other studies have found damage to the hippocampus, caudate nuclei, and the corpus callosum [105] and reduced mamillary body volume and cross-sectional areas of fornix fibers [58] in patients with HF.

Only a few studies have directly examined the association between the adverse brain changes and cognitive deficits observed in HF. Beer et al. [14] found that HF patients performed significantly worse than controls on visuospatial, executive functioning, visual memory and verbal learning tasks. Among these patients, left medial temporal lobe atrophy and deep WMH were significantly associated with impaired scores on measures of cognitive functioning. In another study, Vogels and colleagues [98] demonstrated 
that increased medial temporal lobe atrophy in patients with HF was associated with worse poorer performance on tests of memory, executive function and on the Mini Mental Status Exam independent of cardiovascular risk factors (e.g., hypertension).

\section{Review}

\section{Can cognitive function be improved in HF?}

The trajectory of cognitive impairment and possible decline in HF remains poorly understood. Despite being a known risk factor for degenerative disorders like Alzheimer's disease and vascular dementia (e.g., [75]), two recent studies found that cognitive function remains relatively stable over short time intervals in patients with mild HF $([6,78])$. Moreover, there is research to suggest that the cognitive deficits of HF may be at least partly reversible. For example, a sample of 40 wellmanaged HF patients showed subtle improvements in cognitive function over a 12 month period, particularly in the areas of attention and executive function [87]. Though the exact mechanisms for these cognitive gains are unclear, it appears most likely attributable to improved medical oversight for the study participants [87]. Similarly, other studies have shown improved cognitive function in persons with $\mathrm{HF}$ as a result of medical intervention, including cardiac transplantation $[17,20,43,66]$ pacemaker and cardiac assist device implantation [73, 108], and initiation of treatment with ACE inhibitors [7, 109]. In each case, improved cardiac function was associated with better cognitive function after treatment. Taken together, these results suggest that cognitive impairment in HF may be at least partially reversible through improved cardiovascular function.

\section{Can exercise improve cognitive function in HF?}

Exercise interventions have been linked to improved neurocognitive outcomes across a wide range of patient and healthy samples $[29,71]$. Aerobic exercise is linked to greater gray and white matter volume [30] and increased functional connectivity in the prefrontal cortex [102]. The most consistent effects of aerobic exercise on cognition have been in executive functioning, although several investigations have found improvements in other domains such as attention, visuospatial functioning, processing speed [3, 18, 36]. For example, Voss et al. [101] demonstrated that one-year of exercise training was associated with improved working memory performance in healthy older adults. Even exercise at low intensities has been shown to improve attention [45], memory [81], and concentration [89] in healthy older adults.

\section{Mechanisms for cognitive improvement with exercise} Improvements in cognitive function with exercise are likely related to beneficial brain changes. For example, research has shown that increased cardiorespiratory fitness is associated with reduced brain atrophy [29], the preservation of gray and white matter in the medial-temporal, parietal, and frontal brain regions ([80]), and greater hippocampal volumes [38]. Higher fitness levels have also shown positive effects on functional brain outcomes including greater activation in areas associated with attentional control [31] and greater activity in the frontal and parietal lobes [30]. Moderate- to high- intensity aerobic exercise has produced similar benefits including increases in gray and white matter volume [30] and increased functional connectivity in the prefrontal cortex [102].

Exercise may improve cognitive function in HF patients through other mechanisms. For example levels of C-reactive protein (CRP), normally an inflammatory cytokine associated with acute injury [72], are inversely related to amount of physical activity ([28]; [25, 59]). Exercise is thought to reduce activation of the sympathetic nervous system, which in turn inhibits the release of inflammatory markers, including CRP [28]. This hypothesis has some support in the literature with a heart failure population. Following 6 months of structured exercise, HF patients demonstrated significantly lower levels of CRP, than sedentary controls [68]. The lower levels of CRP may also be related to cognitive function. Research suggests increased levels of CRP are related to impairments in the areas of executive function and memory [50, 70, 93, 107].

Prior work has also identified various circulating biomarkers which may also influence cognitive function in HF. There is little work done on these markers in relation to cardiovascular fitness as most are either associated with eating behavior or newly discovered themselves (i.e. adiponectin). In light of these shortcomings, some research has been conducted examining the influence of physical exercise on biomarkers. Brain derived neurotrophic factor (BDNF) has demonstrated positive relationship with exercise $[42,53]$. This relationship has also been found in an HF population [39], and is important as research indicates cognitive impairment is at least partially caused by decreased BDNF levels [10]. Additionally, BDNF is important for brain health and cognitive function (e.g., $[12,64])$.

Leptin has also been connected to cognitive function [62]. Specifically, leptin has been inversely related to level of cardiovascular fitness levels in both HF [90] and non-HF populations [21, 77]. Ghrelin, is a largely under researched hormone, thus, little evidence exists in relation to cardiovascular fitness. However, one study found ghrelin to have an inverse relationship with cardiovascular fitness [86]. Finally, adiponectin has also been studied in relation to cardiovascular fitness as well. Improvements in cardiovascular fitness have been associated with reduced adiponectin levels [11, 65]. 
In $\mathrm{HF}$, improved cognitive performance with exercise may also be related to comorbid medical conditions. HF is associated with several cardiac and non-cardiac comorbidities; up to $40 \%$ of HF patients have at least five non-cardiac medical conditions [22]. The presence of these comorbid conditions in patients with HF is associated with decreased quality of life, poorer prognosis [67], increased rates of hospitalization, and higher rates of mortality [22]. Common comorbidities of HF include hypertension, type 2 diabetes mellitus, obstructive sleep apnea, chronic obstructive pulmonary disorder, and depression. Each of these conditions has been shown to have an independent association with cognitive deficits, either in HF or non-HF populations, and are likely add to or interact with cardiac dysfunction in HF [49]. Exercise is a common non-pharmacological treatment for a number of comorbid conditions and has been shown to prevent the development or reduce the severity of such conditions both in HF and non-HF populations (e.g., [9, 19, 23, 57, 69]).

\section{Cerebral blood flow as a mechanism for cognitive improvement with exercise in heart failure}

One key mechanism for cognitive gains with exercise which may be particularly important in HF patients is improved cerebral blood flow (CBF). Patients with HF show up to a $30 \%$ reduction in global cerebral blood flow (CBF) [43]. Typically, CBF reductions appear to be greatest in posterior cortical areas [8] but have also been observed in other brain regions important for cognitive function including the frontal, temporal, and parietal lobes [8, 24, 100]. Reduced CBF is also related to poorer cognitive function in HF. In one study, resting regional CBF in elderly patients with HF was compared to healthy age-matched controls using single-photon emission computed tomography (SPECT). Results of this study demonstrated that reduced CBF was common in patients with HF and associated with poorer global cognition, visual and verbal memory, learning, and language tests. Importantly, global cognition was significantly associated with CBF in the posterior cingulate cortex and precuneus [8]. Another study found that global cognition, measured by performance on the Mini Mental Status Exam (MMSE), was significantly positively associated with CBF velocity of the right middle cerebral artery (MCA) in patients with HF [51].

\section{Increased CBF is associated with improved cognitive function in patients with HF}

Intervention studies have shown that increased $\mathrm{CBF}$ is linked to improvements in cognitive function in HF. As above, many of the HF treatments that have been shown to improve cognitive function (e.g., cardiac transplantation, pacemaker implantation, ACE inhibitors) are also known to improve CBF $[27,43,66]$. Several studies have shown that although CBF is reduced at baseline, they become normalized following cardiac transplantation representing an increase of up to $30 \%[27,43,66]$. Similar effects have been observed following implantation of a pacemaker [96]. Finally, in patients with severe HF, CBF improved by approximately $12 \mathrm{ml} / 100 \mathrm{~g}$ per minute following the initiation of treatment with an ACE inhibitor and normalized over time [76]. Given that HF treatment such as cardiac transplantation, pacemaker implantation and ACE inhibitors have been shown to both improve cognitive function and increase $\mathrm{CBF}$, it can be reasoned that increases in $\mathrm{CBF}$ may be an important mechanism for improved cognitive function in HF patients.

\section{Can exercise improve CBF and cognitive function in HF? Evidence for improved CBF with exercise}

Reduced CBF in HF is, in part, the result of decreased cardiac, regulatory, and vascular functioning. In particular, it appears that the combination of reduced cardiac output ( $\mathrm{CO})$ and [83], decreased cerebral autoregulation [46], and impaired endothelial functioning [48] lead to decreased cerebral perfusion and ischemic damage in patients with HF. Importantly, exercise has been shown to improve cardiac and vascular function $[41,44]$ in HF patients potentially leading to increased CBF. See Fig. 1.

Moderate- to high-intensity aerobic exercise has been shown to improve exercise capacity and increase $\mathrm{VO}_{2}$ max in patients with HF $[34,52,54,55]$ and is also associated with a number of cardiac and vascular improvements among patients with HF. In terms of cardiac functioning, the benefits of moderate- to high intensity aerobic exercise include decreased resting $\mathrm{HR}[34,37,44,85]$, increased CO $[44,92]$ and stroke volume $[34,37,44]$ and reduced resting LV end-diastolic diameter [44]. In terms of vascular functioning, benefits include decreased peripheral resistance and sympathetic activation [44], increased vasodilatory capacity [63], blood flow [44] and improved endothelial function [63].

Exercise at lower intensities is also related to improved $\mathrm{VO}_{2}$ max and increased exercise capacity $[15,33,56,91]$ though research on its association with other cardiac and vascular factors is limited. One study also demonstrated that moderate-intensity (50\% max work rate) cycling was associated with improved HR recovery while participants who completed high-intensity interval training did not experience such improvement [33].

A growing body of literature shows aerobic exercise has beneficial effects on CBF in non-HF populations [2, 47]. Specifically, Hellstrom et al. [47] demonstrated that global CBF increased during moderate exercise in a sample of healthy adults. Another study found higher blood flow velocity in the middle cerebral artery among endurancetrained men when compared to sedentary men [2]. 


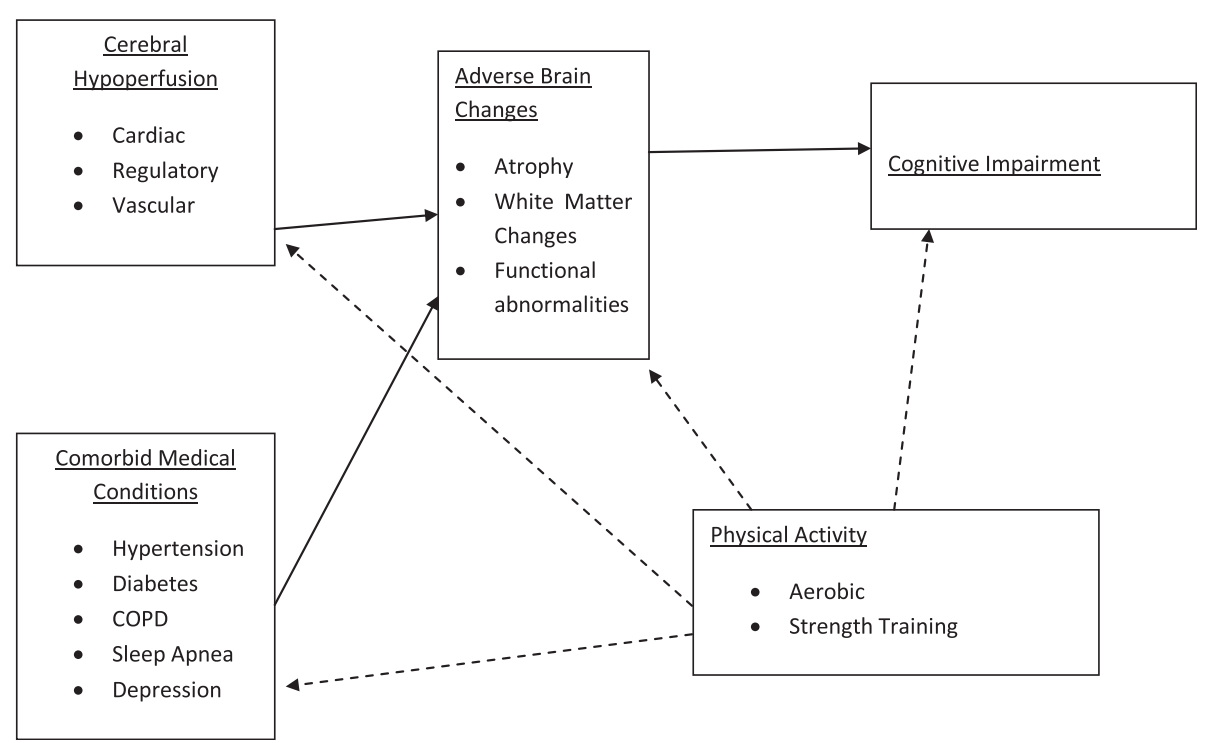

Fig. 1 Physical Activity for the Improvement of Cognitive function in Heart Failure Solid lines represent pathways leading to poorer health and cognitive outcomes. Broken lines indicate pathways for improved outcomes

Similarly, a recent study demonstrated higher resting CBF levels among older master athletes when compared to sedentary older adults [95]. It has also been demonstrated that 12 weeks of aerobic exercise was associated with both improved $\mathrm{CBF}$ and cognition in healthy older adults [26]. Although no study to date has examined whether exercise can improve CBF in patients with HF, one study has examined this association in a sample of older adults with cardiovascular disease (CVD) [88]. In this study, 12 weeks of exercise was associated with improved CBF velocity. The authors also found that attention, executive function, and memory performance improved, though these improvements were not related to CBF velocity.

\section{Evidence for cognitive improvement with exercise in HF} There has been some research to suggest that cognition can improve following exercise in HF. For example, Tanne et al. [94] examined the benefits of twice weekly aerobic exercise at $60-70 \%$ of maximal heart rate on cognitive function in HF patients. Results demonstrated that exercise was associated with improvements in attention/psychomotor speed and executive function. Unfortunately, these findings are limited by a small number of participants in the intervention $(n=18)$ and control group $(n=5)$ and potential baseline differences in cognitive function between these groups were not examined. Additionally, CBF was not measured.

Consistent with these possible benefits of exercise, two recent studies have examined the link between fitness levels and cognitive function in HF. One study found that greater metabolic equivalents (METs) from a standardized stress test was related to better performance on measures of attention $(\beta=.41, p=.03)$, executive function $(\beta=.37, p=.04)$, and memory $(\beta=.46, p=.04)$ even after controlling for important medical and demographic characteristics, [40]. Similarly, another study examined the association between exercise capacity, estimated by distance walked on the 6-min walk test, and cognitive function in 80 elderly patients with HF. As above, results showed that greater exercise capacity was associated with better cognitive function [13].

\section{Conclusion}

Overall, the current evidence seems to suggest that the cognitive benefits through exercise could extend to persons with HF. In particular, findings from interventional studies (i.e., pacemaker implant, cardiac transplant, treatment with ACE inhibitors) suggest that improved CBF can lead to improved cognitive functioning in patients with HF. Exercise may also lead to similar improvements through its beneficial effects on cardiac and vascular functioning in $\mathrm{HF}$ patients, potentially leading to improved $\mathrm{CBF}$ and ultimately, improved cognitive function. Existing research on the cognitive benefits of exercise in HF is limited, but promising. The search for interventions that can improve cognitive functioning or prevent further decline in patients with HF are much needed, as the societal implications of such an intervention would be substantial.

Competing interests

The authors declare that they have no competing interests.

\section{Authors' contributions}

RG was responsible for conceptualization, writing, and editing of the manuscript. AF contributed to the writing of the manuscript. JG contributed to the conceptualization and editing of the manuscript. All authors read and approved the final manuscript. 


\section{Acknowledgments}

The authors have no acknowledgments.

\section{Disclosures}

Rachel Galioto declares no conflicts of interest. Andrew Fedor Declares no conflict of interest John Gunstad declares no conflict of interest. This article does not contain any studies with human or animal subjects performed by any of the authors.

Received: 6 July 2015 Accepted: 30 September 2015 Published online: 23 October 2015

\section{References}

1. Adams KF, Zannad F. Clinical definition and epidemiology of advance heart failure. Am Heart J. 1998;135:S204-15.

2. Ainslie PN, Cotter JD, George KP, Lucas SJE, Murrell C, Shave R, et al. Elevation in cerebral blood flow velocity with aerobic fitness throughout healthy human ageing. J Physiol. 2008;586:4005-10.

3. Albinet C, Boucard G, Bouquet C, Audiffren M. Increased heart rate variability and executive performance after aerobic training in the elderly. Eur J Appl Physiol. 2010;109:617-24.

4. Almeida JRC, Alves TCTF, Wajngarten M, Rays J, Castro CC, Cordeiro Q, et al. Late-life depression, heart failure, and frontal white matter hyperintensity: a structural magnetic resonance imaging study. Braz J Med Biol Res. 2005;38:431-6.

5. Almeida OP, Beer C, Lautenschlager NT, Arnolda L, Alfonso H, Flicker L. Two-year course of cognitive function and mood in adults with congestive heart failure and coronary artery disease: the Heart-Mind Study. Int Psychogeriatr 2012; 24:38-47.

6. Almeida OP, Flicker $L$. The mind of a failing heart: a systematic review of the association between congestive heart failure and cognitive functioning. Int Med J. 2001;31:290-5.

7. Almeida OP, Tamai S. Clinical treatment reverses attentional deficits in congestive heart failure. BMC Geriatr. 2001;1:2.

8. Alves TCTF, Rays J, Fraguas R, Wajngarten M, Meneghetti JC, Prando S, et al. Localized cerebral blood flow reductions in patients with heart failure: a study using 99mTc-HMPAO SPECT. J Neuroimaging. 2005;15:150-6.

9. Alves TC, Rays J, Telles RM, Júnior RF, Wajngarten M, Romano BW, et al. Effects of antidepressant treatment on cognitive performance in elderly subjects with heart failure and comorbid major depression: an exploratory study. Psychosomatics. 2007:48:22-30.

10. Appel SH. A unifying hypothesis for the cause of amyotrophic lateral sclerosis, Parkinsonism, and Alzheimer's disease. Ann Neurol. 1981;10:499-505.

11. Arsenault BJ, Cartier A, Cote M, Lemieux I, Tremblay A, Bouchard C, et al. Body composition, cardiorespiratory fitness and low grad inflammation in middle aged men and women. Am J Cardiol. 2009;104:240-6.

12. Babaei $P$, Azali Almdari K, Soltani Tehrani B, Damirchi A. Effect of six weeks of endurance exercise and following detraining on serum brain derived neurotrophic factor and memory performance in middle aged males with metabolic syndrome. J Sports Med Phys Fitness. 2013;53:437-43.

13. Baldasseroni S, Mossello E, Romboli B, Orso F, Colombi C, Fumagalli S, et al. Relationship between cognitive function and 6-minute walking test in older outpatients with chronic heart failure. Aging Clin Exp Res. 2010;22:308-13.

14. Beer C, Ebenezer E, Fenner S, Lautenschlager NT, Arnolda L, Flicker $L$, et al. Contributors to cognitive impairment in congestive heart failure: a pilot case-control study. Int Med J. 2009;39:600-5

15. Belardinelli R, Scocco V, Mazzanti M, Purcaro A. Effects of aerobic training in patients with moderate chronic heart failure. G Ital Cardiol. 1992;22:919-30.

16. Bennet SJ, Pressler ML, Hays L, Firestine L, Huster GA. Psychosocial variables and hospitalization in persons with chronic heart failure. Prog Cardiovasc Nurs. 1997;12:4-11.

17. Bennet $S$, Sauve M. Cognitive deficits in patients with heart failure: A review of the literature. J Cardiovasc Nurs. 2003;18:219-42.

18. Blumenthal JA, Emery CF, Madden DJ, Schniebolk S, Walshriddle M, George $L$, et al. Long-term effects of exercise on psychological functioning in older men and women. J Gerontol. 1991;46:352-61.

19. Blumenthal JA, Sherwood A, Gullette EC, Babyak M, Waugh R, Georgiades A, et al. Exercise and weight loss reduce blood pressure in men and women with mild hypertension: effects on cardiovascular, metabolic, and hemodynamic functioning. Arch Intern Med. 2000;160:1947-58.
20. Bornstein RA, Starling RC, Myerowitz PD, Haas GJ. Neuropsychological function in patients with end-state heart failure before and after cardiac transplant. Acta Neurol Scand. 1995;4:260-5.

21. Bouassida A, Chamari K, Zaouali M, Feki Y, Zbidi A, Tabka Z. Review on leptin and adiponectin responses and adaptations to acute and chronic exercise. Br J Sports Med. 2010;44:620-30.

22. Braunstein JB, Anderson GF, Gerstenblith G, Weller W, Niefeld M, Herbert R, et al. Noncardiac comorbidity increases preventable hospitalizations and mortality among medicare beneficiaries with chronic heart failure. J Am Coll Cardiol. 2003:42:1226-33.

23. Brønstad, E., Tjonna, E., Rognmo, O., Dalen, H., Heggli, A.M., Wisloff, U, Steinshamn S. Aerobic exercise training improves right- and left ventricular systolic function in patients with COPD. COPD, 2012 [Epub ahead of print]

24. Burra P, Senzolo M, Pizzolato G, Tursi V, Livi U, Chierichetti F, et al. Frontal cerebral blood flow is impaired in patients with heart transplantation. Transpl Int. 2002;15:459-62.

25. Cardoso CRL, Maia MDL, de Oliveira FP, Leite NC, Salles GF. High fitness is associated with a better cardiovascular risk profile in patients with type 2 diabetes mellitus. Hypertens Res. 2011;34:856-61.

26. Chapman SB, Aslan S, Spence JS, DeFina LF, Keebler MW, Didehbani N, et al. Shorter term aerobic exercise improves brain, cognition, and cardiovascular fitness in aging. Front Aging Neurosci. 2013;5:75.

27. Choi BR, Kim JS, Yang YJ, Park K, Lee CW, Kim Y, et al. Factors associated with decreased cerebral blood flow in congestive heart failure secondary to idiopathic dilated cardiomyopathy. Am J Cardiol. 2006;97:1365-9.

28. Church TS, Barlow CE, Earnest CP, Kampert JB, Priest EL, Blair SN. Associations between cardiorespiratory fitness and C-reactive protein in men. Arterioscler Thromb Vasc Biol. 2002:22:1869-76.

29. Colcombe SJ, Erickson KI, Raz N, Webb AG, Cohen NJ, McAuley E, et al. Aerobic fitness reduces brain tissue loss in aging humans. J Gerontol Series A: Biol Sci Med Sci. 2003;58:176-80.

30. Colcombe SJ, Erickson KI, Scalf PE, Kim JS, Prakash R, McAuley E, et al. Aerobic exercise training increases brain volume in aging humans. Journal of Gerontology. Series A: Biol Sci Med Sci. 2006;61:1166-70.

31. Colcombe SJ, Kramer AF, Erickson KI, McAuley E, Cohen NJ, Webb A, et al. Cardiovascular fitness, cortical plasticity and aging. Proc National Acad Sci USA. 2004;101:3316-21.

32. Dardiotis, E., Giamouzis, G., Matrogiannis, D., Vogiatzi, C., Skoularigis, J., Triposkiadis, F., \& Hadjigeorgiou, G.M. Cognitive impairment in heart failure. Cardiol Res Prac. 2012 [Epub ahead of print].

33. Dimopoulos S, Anastasiou-Nana M, Sakellarious D, Drakos S, Kapsimalakou S, Maroulidis $G$, et al. Effects of exercise rehabilitation program on heart rate recovery in patients with chronic heart failure. Eur J Cardiovasc Prev Rehab. 2006;13:67-73.

34. Dubach P, Myers J, Dziekan G, Goebbels U, Reinhart W, Muller P, et al. Effect of high intensity exercise training on central hemodynamic responses to exercise in men with reduced left ventricular function. J Am Coll Cardiol. 1997;29:1591-8.

35. Dunlay SM, Redfield MM, Weston SA, Therneau TM, Long KH, Shah ND, et al. Hospitalizations after heart failure diagnosis: a community perspective. J Am Coll Cardiol. 2009;54:1695-702.

36. Dustman RE, Ruhling RO, Russell EM, Shearer DE, Bonekat HW, Shigeoka JW, et al. Aerobic exercise training and improved neuropsychological function of older individuals. Neurobiol Aging. 1984;5:35-42.

37. Erbs S, Linke A, Gielen S, Fiehn E, Walther $C, Y u$ J, et al. Exercise training in patients with severe chronic heart failure: impact on left ventricular performance and cardiac size. A retrospective analysis of the Leipzig Heart Failure Training Trial. Eur J Cardiovasc Prev Rehab. 2003;10:336-44.

38. Erickson Kl, Prakash RS, Voss MW, Chaddock L, Hu L, Morris KS, et al. Aerobic fitness is associated with hippocampal volume in elderly humans. Hippocampus. 2009;19:1030-9.

39. Fukishima A, Kinugawa S, Homma T, Masaki Y, Furihata T, Yokota T, et al. Decreased serum brain-derived neurotrophic factor levels are correlated with exercise intolerance in patients with heart failure. Int J Cardiol. 2013;168:e412.

40. Garcia S, Alosco ML, Spitznagel MB, Cohen R, Raz N, Sweet L, et al. Cardiovascular fitness is associated with cognitive performance in heart failure patients enrolled in cardiac rehabilitation. BMC Cardiovasc Disord. 2013;13:29.

41. Gordon NF, Scott CB, Levine BD. Comparison of single versus multiple lifestyle interventions: are the antihypertensive effects of exercise training and diet-induced weight loss additive? Am J Cardiol. 1997;79:763-7. 
42. Griffin EW, Mullally S, Foley C, Warmington SA, O'Mara SM, Kelly AM. Aerobic exercise improves hippocampal function and increases BDNF in the serum of young adult males. Physiol Behav. 2011;104:934-41.

43. Gruhn N, Larsen FS, Boesgaard S, Knudsen GM, Mortensen SA, Thomsen G, et al. Cerebral blood flow in patients with chronic heart failure before and after heart transplantation. Stroke. 2001;32:2530-3.

44. Hambrecht R, Gielen S, Linke A, Fiehn E, Yu J, Walther C, et al. Effects of exercise training on left ventricular function and peripheral resistance in patients with chronic heart failure: a randomized trial. J Am Med Assoc. 2000;283:3095-101.

45. Hassmen P, Ceci R, Backman L. Exercise for older women: a training method and its influence on physical and cognitive performance. Eur J Appl Physiol Occup Physiol. 1992;64:460-6.

46. Heckman GA, Patterson CJ, Demers C, St. Onge J, Turpie ID, McKelvie RS. Heart failure and cognitive impairment: Challenges and opportunities. J Clin Intervent Aging. 2007;176:644-5.

47. Hellstrom G, Fischer-Colbrie W, Wahlgren NG, Jogestrand T. Carotid artery blood flow and middle cerebral artery blood flow velocity during physical exercise. J Appl Physiol. 1996;81:413-8

48. Hoth KF, Tate DF, Poppas A, Forman DE, Gunstad J, Moser DJ, et al. Endothelial function and white matter hyperintensities in older adults with cardiovascular disease. Stroke. 2007;38:308-12.

49. Hoth KF. Heart failure and cognition. In: Cohen RA, Gunstad J, editors. Neuropsychology and Cardiovascular Disease. New York, NY: Oxford; 2010. p. 204-17.

50. Jefferson AL, Massaro JM, Beiser AS, Seshadri S, Larson MG, Wolf PA, et al. Inflammatory markers and neuropsychological functioning: The Framingham Heart Study. Neuroepidemiology. 2011;37:21-30.

51. Jesus PA, Vieira-de-Melo RM, Reis FJ, Viana LC, Lacerda A, Dias JS, et al. Cognitive dysfunction in congestive heart failure: transcranial Doppler evidence of microembolic etiology. Arq Neuropsiquiatr. 2006;64:207-10.

52. Jetté M, Heller R, Landry F, Blümchen G. Randomized 4-week exercise program in patients with impaired left ventricular function. Circulation. 1991;84:1561-7.

53. Jung SH, Kim J, Davis JM, Blair SN, Cho H. Association among basal serum BDNF, cardiorespiratory fitness and cardiovascular disease risk factors in untrained healthy Korean men. Eur J Appl Physiol. 2011;111:303-11.

54. Keteyian SJ, Levine AB, Brawner CA, Kataoka T, Rogers FJ, Schairer JR, et al. Exercise training in patients with heart failure. A randomized, controlled trial. Ann Intern Med. 1996;124:1051-7.

55. Keteyian SJ, Brawner CA, Schairer JR, Levine TB, Levine AB, Rogers FJ, et al. Effects of exercise training on chronotropic incompetence in patients with heart failure. Am Heart J. 1999;138:233-40.

56. Kiilavuori K, Sovijärvi A, Näveri $H$, Ikonen $T$, Leinonen $H$. Effects of physical training on exercise capacity and gas exchange in patients with chronic heart failure. Chest. 1996;110:985-91.

57. Kline CE, Crowley EP, Ewing GB, Burch JB, Blair SN, Durstine JL, et al. The effect of exercise training on obstructive sleep apnea and sleep quality: a randomized controlled trial. Sleep. 2011;34:1631-40.

58. Kumar R, Woo MA, Birrer BV, Macey PM, Fonarow GC, Hamilton MA, et al. Mammillary bodies and fornix fibers are injured in heart failure. Neurobiol Disord. 2009;33:236-42.

59. Lavie CJ, Church TS, Milani RV, Earnest CP. Impact of physical activity, cardiorespiratory fitness, and exercise training on markers of inflammation. J Cardiopulm Rehab Prev. 2011;31:137-45.

60. Lee CW, Lee JH, Lim TH, Yang HS, Hong MK, Song JK, et al. Prognostic significance of cerebral metabolic abnormalities in patients with congestive heart failure. Circulation. 2001;103:2784-7.

61. Levy D, Kenchaiah S, Larson MG, Benjamin EJ, Kupka MJ, Ho KK, et al. Long-term trends in the incidence of and survival with heart failure. N Engl J Med. 2002:347:1397-402

62. Lieb W, Beiser AS, Vasan RS, Tan ZS, Au R, Harris TB, et al. Association of plasma leptin levels with incident Alzheimer's disease and MRI measures of brain aging: the Framingham Study. J Am Med Assoc. 2009;302:2565-72.

63. Linke A, Schoene N, Gielen S, Hofer J, Erbs S, Schuler G, et al. Endothelial dysfunction in patients with chronic heart failure: systemic effects of lower-limb exercise training. J Am Coll Cardiol. 2001;37:392-7.

64. Lu B, Nagappan G, Lu Y. BDNF and synaptic plasticity, cognitive function, and dysfunction. Handb Exp Pharmacol. 2014;220:223-50.

65. Martinez EC, Fortes M, Anjos LA. Influence of nutritional status and VO2Max on adiponectin levels in men older than 35 years. Arquivos Brasilieros de Cardiologia. 2011:96:471-6.

66. Massaro AR, Dutra AP, Almeida DR, Diniz RV, Malheiros SM. Transcranial Doppler assessment of cerebral blood flow: effect of cardiac transplantation. Neurology. 2006;10:124-6.
67. McMurray JJ, Adamopoulos S, Anker SD, Auricchio A, Bohm M, Dickstein K, et al. ESC Guidelines for the diagnosis and treatment of acute and chronic heart failure 2012: the task force for the diagnosis and treatment of acute and chronic heart failure 2012 of the European society of cardiology. Developed in collaboration with the heart failure association (HFA) of the ESC. Eur J Heart Fail. 2012;14:803-69.

68. Meirelles LR, Matsuura C, Resende AD, Salgado AA, Pereira NR, Coccarrelli PG, Brunini TM. Chronic exercise leads to antiaggregant, antioxidant and anti-inflammatory effects in heart failure patients. European J Prevent Cardiol. 2013 [Epub ahead of print].

69. Mikus CR, Oberlin DJ, Libla J, Boyle LJ, Thyfault JP. Glycaemic control is improved by 7 days of aerobic exercise training in patients with type 2 diabetes. Diabetologia. 2011;55:1417-23.

70. Noble JM, Manly JJ, Schupf N, Tang MX, Mayeux R, Luchsinger JA. Association of C-reactive protein with cognitive impairment. Arch Neurol. 2010;67:87-92

71. Palleschi L, Vetta F, De Gennaro E, Idone G, Sottosanti G, Gianni W, et al. Effect of aerobic training on the cognitive performance of elderly patients with senile dementia of Alzheimer type. Arch Gerontol Geriatr. 1996;22:47-50

72. Pepys MB, Hirschfield GH. C-reactive protein: a critical update. J Clin Invest. 2003;111:1805-12.

73. Petrucci RJ, Wright S, Naka Y, Idrissi KA, Russell SD, Dordunoo D, et al. Neurocognitive assessments in advanced heart failure patients receiving continuous-flow Left ventricular assist devices. J Heart Lung Transplan. 2009;28: 542-549.

74. Pressler SJ, Kim J, Riley P, Ronis DL, Gradus-Pizlo I. Memory dysfunction, psychomotor slowing and decreased executive function predict mortality in patients with heart failure and low ejection fraction. J Cardiovasc Fail. 2010;16:750-60

75. Qiu C, Wingblad B, Marengoni A, Klarin I, Fastbom J, Fratiglioni L. Heart failure and risk of dementia and Alzheimer disease: a population-based cohort study. Arch Intern Med. 2006;166:1003-8.

76. Rajagopalan B, Raine AEG, Cooper R, Ledingham JG. Changes in cerebra blood flow in patients with severe congestive cardiac failure before and after catopril treatment. Am J Med. 1984;76:86-90.

77. Reseland JE, Anderssen SA, Solvoll K, Hjermann I, Urdal P, Holme I, et al. Effects of long term changes in diet and exercise on plasma leptin concentrations. Am J Clin Nutr. 2001;73:240-5.

78. Riegel B, Lee CS, Glaser D, Moetler ST. Patterns of change in cognitive function over six months in adults with chronic heart failure. Cardiol Res Pract. 2012 [Epub ahead of print].

79. Roger VL, Go AS, Lloyd-Jones DM, Benjamin EJ, Berry JD, Borden WB, et al. Heart disease and stroke statistics - 2012 update: a report from the American Heart Association. Circulation. 2012;125:e2-220.

80. Rovio S, Spulber G, Nieminen LJ, Niskanen E, Winblad B, Tuomilehto J, et al. The effect of midlife physical activity on structural brain changes in the elderly. Neurobiol Aging. 2010;31:1927-36.

81. Ruscheweyh R, Willemer C, Kruger K, Duning T, Warnecke T, Sommer J, et al Physical activity and memory functions: an interventional study. Neurobiol Aging. 2011;32:1304-19.

82. Rusinaru D, Mahjoub H, Goissen T, Massy Z, Peltier M, Tribouilloy C. Clinical features and prognosis of heart failure in women. A 5-year prospective study. Int J Cardiol. 2009;133:327-35.

83. Saxena PR, Schoemaker RG. Organ blood flow protection in hypertension and congestive heart failure. Am J Med. 1993;94:4S-12.

84. Schmidt R, Fazekas F, Offenbacher H, Dusleag J, Lechner $\mathrm{H}$. Brain magnetic resonance imaging and neuropsychological evaluation of patients with idiopathic dilated cardiomyopathy. Stroke. 1991;22:195-9.

85. Silva MS, Bocchi EA, Guimaraes GV, Padovani CR, Silva MH, Pereira SF, et al, Benefits of exercise training in the treatment of heart failure: study with a control group. Arq Bras Cardiol. 2002;79:351-62.

86. Spitznagel MB, Benitez A, Updegraff J, Potter V, Alexander T, Glickman E, et al. Serum ghrelin is inversely associated with cognitive function in a sample of non-demented elderly. Psychiatry Clin Neurosci. 2010;64:608-11.

87. Stanek KM, Gunstad J, Paul RH, Poppas A, Jefferson AL, Sweet LH, et al. Longitudinal cognitive performance in older adults with cardiovascular disease: Evidence for improvement in heart failure. J Cardiovasc Nurs. 2009;24:192-7.

88. Stanek KM, Gunstad J, Spitznagel MB, Waechter D, Hughes JW, Luyster F, et al. Improvements in cognitive function following cardiac rehabilitation for older adults with cardiovascular disease. Int J Neurosci. 2011;121:86-93. 
89. Stevenson JS, Topp R. Effects of moderate and low intensity long-term exercise by older adults. Res Nurs Health. 1990;13:209-18.

90. Straburzynska-Migaj E, Gwizdala A, Siniawski A, Ochotny R, Grajek S. Leptin and inflammation in patients with chronic heart failure. Kardiol Pol. 2010;68:1243-7.

91. Sturm B, Quittan M, Wiesinger GF, Stanek B, Frey B, Pacher R. Moderateintensity exercise training with elements of step aerobics in patients with severe chronic heart failure. Arch Phys Med Rehabil. 1999:80:746-50.

92. Sullivan MJ, Higginbotham MB, Cobb FR. Exercise training in patients with severe left ventricular dysfunction. Hemodynamic Metabol Effects Circ. 1988;78:506-15

93. Sweat V, Starr V, Bruehl H, Arentoft A, Tirsi A, Javier E, et al. C-reactive protein is linked to lower cognitve performace in overweight and obese women. Inflammation. 2008;31:198-207.

94. Tanne D, Freirmark D, Poreh A, et al. Cognitive Function in severe congestive heart failure before and after an exercise training program. Int J Cardiol. 2005:103:145-9.

95. Thomas BP, Yezhuvath US, Tseng BY, Liu P, Levine BD, Zhang R, et al. Life-long aerobic exercise preserved baseline cerebral blood flow but reduced vascular reactivity to CO2. J Magn Reson Imaging. 2013;38:1177-83.

96. Van Bommel RJ, Marsan NA, Koppen H, Delgado V, Borleffs CJ, Ypenburg C, et al. Effect of cardiac resynchronization therapy on cerebral blood flow. Am J Cardiol. 2010;106:73-7.

97. Vogels RLC, Scheltens P, Schroeder-Tanka JM, Weinstein HC. Cognitive impairment in heart failure: a systematic review of the literature. Eur J Heart Fail. 2007:9:440-9.

98. Vogels RLC, Oosterman JM, van Harten B, Scheltens P, van der Flier WM, Schroeder-Tanka JM, et al. Profile of cognitive impairment in chronic heart failure. J Am Geriatric Soc. 2007;55:1764-70.

99. Vogels RLC, van der Flier WM, van Harten B, Gouw AA, Scheltens $P$, Schroeder-Tanka JM, et al. Brain magnetic resonance imaging abnormalities in patients with heart failure. Eur J Heart Fail. 2007;9:1003-9.

100. Vogels RLC, Oosterman JM, Laman DM, Gouw AA, Schroeder-Tanka JM, Scheltens $P$, et al. Transcranial doppler blood flow assessment in patients with mild heart failure: correlates with neuroimaging and cognitive performance. Congestive Heart Failure. 2008;14:61-5.

101. Voss MW, Heo S, Prakash RS, Erickson Kl, Alves H, Chaddock L, Kramer AF. The influence of aerobic fitness on cerebral white matter integrity and cognitive function in older adults: Results of a one-year exercise intervention. Human Brain Mapp. 2012 [Epub ahead of print].

102. Voss MW, Prakash RS, Erickson KI, Basak C, Chaddock L, Kim JS, et al. Plasticity of brain networks in a randomized intervention trial of exercise training in older adults. Front Aging Neurosci. 2010;2:1-17.

103. Witt BJ, Gami AS, Ballman KV, Brown Jr RD, Meverden RA, Jacobsen SJ, et al. The incidence of ischemic stroke in chronic heart failure: a meta-analysis. J Card Fail. 2007:13:489-96.

104. Wolf PA, Kannel WB, McNamara PM. Occult impaired cardiac function, congestive heart failure, and risk of thrombotic stroke: the Framingham Study. Neurology. 1970;20:373.

105. Woo MA, Kumar R, Macey PM, Fonarow GC, Harper RM. Brain injury in autonomic, emotional, and cognitive regulatory areas in patients with heart failure. J Car Fail. 2009; 15(3): 214-23.

106. Woo MA, Macey PM, Fonarow GC, Hamilton MA, Harper RM. Regional brain gray matter loss in heart failure. J Appl Physiol. 2003;95:677-84.

107. Yaffe K, Kanaya A, Lindquist K, Simonsick EM, Harris T, Shorr Rl, et al. The metabolic syndrome, inflammation, and risk of cognitive decline. J Am Med Assoc. 2004;292:2237-42.

108. Zimpfer D, Wieselthaler G, Czerny M, Fakin R, Haider D, Zrunek P, et al. Neurocognitive function in patients with ventricular assist devices: a comparison of pulsatile and continuous blood flow devices. Am Soc Artificial Intern Organs J. 2006;52:24-7.

109. Zuccala G, Onder G, Marzetti E, Monaco MR, Cesari M, Cocchi A, et al. Use of angiotensin-converting enzyme inhibitors and variations in cognitive performance among patients with heart failure. Eur Heart J. 2005;26:226-33.

\section{Submit your next manuscript to BioMed Central and take full advantage of:}

- Convenient online submission

- Thorough peer review

- No space constraints or color figure charges

- Immediate publication on acceptance

- Inclusion in PubMed, CAS, Scopus and Google Scholar

- Research which is freely available for redistribution 